Check for updates

Cite this: RSC Adv., 2020, 10, 38727

Received 14th August 2020

Accepted 13th October 2020

DOI: 10.1039/d0ra07012b

rsc.li/rsc-advances

\section{Enzymatic preparation of glycerophosphatilcholine catalyzed by combinational phospholipases: a comparative study of concerted versus stepwise catalysis}

\begin{abstract}
Shaohua Liang, Shukun Wang, Yannan Meng and Cong Sun (iD *
Glycerophosphatilcholine (GPC) is widely applied in medical, pharmaceutical, food and cosmetic industries. Due to the lack of natural resources, enzymatic preparation of GPC has been explored in recent years. This study aimed to investigate and compare the effects of different addition methods of combinational phospholipases $\left(\mathrm{PLA}_{1}\right.$ and $\mathrm{PLA} \mathrm{A}_{2}$ ) and various process parameters (time, temperature, $\mathrm{pH}$, substrate concentrate, enzyme load, and stirring rate) on the preparation of GPC. The results showed that compared with concerted catalysis, the catalytic efficiency of adding PLA $\mathrm{A}_{2}$ and then $\mathrm{PLA}_{1}\left(\mathrm{PLA}_{2} \rightarrow \mathrm{A}_{1}\right)$ was higher, whereas that of adding $P L A_{1}$ and then $P L A_{2}$ was lower. The main reason might be that the method of $P L A_{2} \rightarrow A_{1}$ could reduce acyl migration and the competition between PLA $A_{1}$ and PLA $A_{2}$, which was beneficial to improve the GPC yield and shorten the reaction time. This paper could provide a novel approach for the future preparation of GPC catalyzed by combinational phospholipases.
\end{abstract}

\section{Introduction}

Glycerophosphatilcholine (GPC) is the intermediate product of phospholipid decomposition, the precursor of neurotransmitter acetylcholine and phosphatidylcholine (PC), and also the precursor of membrane phospholipid..$^{1-3}$ Many studies have shown that GPC can promote the secretion of growth hormone to treat Alzheimer's disease, and it can also increase the release of individual hormones to treat cognitive disorders, schizophrenia and emotional disorders. In addition, GPC also has the functions of treating cardiovascular diseases and promoting non rapid eye movement sleep. ${ }^{4-9}$ Therefore, GPC is widely applied in medical, pharmaceutical, food and cosmetic industries. ${ }^{\mathbf{1 0}}$

In general, there are three methods for preparing GPC, including animal tissue extraction, chemical and enzymatic methods. Natural GPC exists in the liver, brain and semen of animals. ${ }^{11}$ However, these natural resources are limited and the extraction yield is low, which is not suitable for large-scale industrial application. ${ }^{12-14}$ The purity and yield of GPC prepared by chemical catalysis is generally high, but it is also accompanied by toxic reagents or high energy consumption. ${ }^{15}$ Marrapu et al. prepared GPC from soybean/yolk powder phospholipid catalyzed by tetra butyl ammonium, the yield of which could reach 99\%. ${ }^{16}$ Park et al. used benzyl alcohol to protect

College of Food Science and Engineering, Henan University of Technology, Lianhua Road 100, Zhengzhou 450001, Henan Province, P. R. China. E-mail: suncong0511@ haut.edu.cn; Fax: +86-371-67758022; Tel: +86-371-67758022 hydroxyl group, and prepared GPC by five-steps method. ${ }^{\mathbf{1 0}}$ Although this method utilized the non-toxic reagents, the process was quite complex and the reaction temperature reached $120^{\circ} \mathrm{C}$.

Enzyme is considered as a kind of environment-friendly and high-effective catalyst, which has been generally applied in the preparation of GPC in recent years. ${ }^{17,18}$ The common phospholipases are mainly phospholipase $\mathrm{A}_{1}$ (PLA $)$, phospholipase $\mathrm{A}_{2}\left(\mathrm{PLA}_{2}\right)$, phospholipase $\mathrm{B}$ (PLB), phospholipase C (PLC) and phospholipase D (PLD). ${ }^{19-22}$ Their action sites are shown in Fig. 1. In terms of enzymatic preparation of GPC, single phospholipase is generally used. Zhang et al. studied

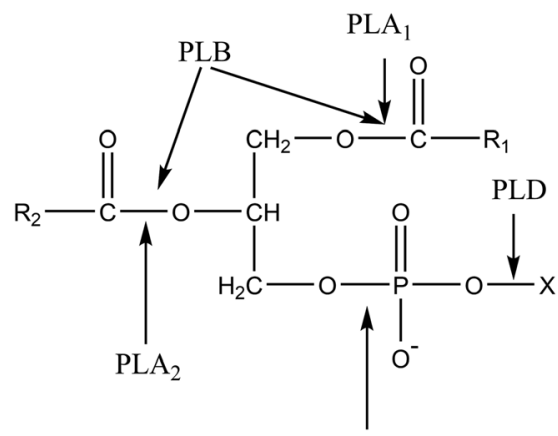

PLC

Fig. 1 The action sites of four phospholipases. PLA, phospholipase $A_{1}$; PLA 2 , phospholipase $A_{2}$; PLB phospholipase B; PLC, phospholipase $C$; PLD, phospholipase $D$. 
the preparation of GPC by hydrolyzing soybean powder phospholipid with $\mathrm{PLA}_{1}$ as catalyst in aqueous system. ${ }^{23}$ Under the optimum conditions, the yield of GPC reached $94.5 \%$. Lu et al. used a fed-batch process to catalyze the egg yolk lecithin with $\mathrm{PLA}_{1} \cdot{ }^{24}$ The results showed that Tween 20 was the most effective surfactant for enhancing GPC concentration, and the GPC was obtained with a yield of $91.36 \%$ within $3 \mathrm{~h}$. Kim et al. prepared GPC via Novozyme 435 catalyzed hydrolysis of soy phosphatidylcholine or a fractionated soy lecithin, in which a water-soluble fraction containing $98.6 \%$ of GPC was obtained. ${ }^{25}$ Although the yield of GPC was quite high with single phospholipase, high purity of substrate, such as lecithin, powder phospholipid and other high concentration phospholipids, was required, which led to high cost of production. In theory, GPC preparation catalyzed by single phospholipase is inefficient due to acyl migration. ${ }^{26}$ Take PLA $_{1}$ for example, the $s n$-2-lysophosphatidylcholine ( $s n$-2-LPC) generated by the initial hydrolysis is easily transformed into $s n$-1-lysophosphatidylcholine (sn-1-LPC) via acyl migration. Then, the $s n$-1-LPC was catalyzed by $\mathrm{PLA}_{1}$ to prepare GPC. However, the $s n-1-\mathrm{LPC}$ or $s n$-2-LPC generated by acyl migration have negative effects on the reaction rate. Therefore, Blasi et al. have attempted to add Lipozyme IM and $\mathrm{PLA}_{2}$ at the same time to the egg yolk microemulsion system, and the $94 \%$ GPC yield was obtained after $48 \mathrm{~h}$ at $35^{\circ} \mathrm{C}^{27}$ Although the GPC yield could reach a high level, the reaction time was so long, which might be due to acyl migration and competition between the two phospholipases. Thus, it may be a feasible method to prepare GPC by stepwise catalysis of combinational phospholipases.
In this work, the preparation of GPC was carried out in the presence of two phospholipases ( $\mathrm{PLA}_{1}$ and $\mathrm{PLA}_{2}$ ) with soybean concentrated phospholipid as raw material. The influences of the three adding methods of $\mathrm{PLA}_{1}$ and $\mathrm{PLA}_{2}$ (including $\mathrm{PLA}_{1}+$ $\mathrm{A}_{2}, \mathrm{PLA}_{1} \rightarrow \mathrm{A}_{2}$ and $\mathrm{PLA}_{2} \rightarrow \mathrm{A}_{1}$ ) on the yield of GPC under various process parameters were investigated and compared to obtain a more efficient method.

\section{Materials and methods}

\subsection{Materials}

Soybean concentrated phospholipid was purchased from COFCO Excel Joy (Tianjin) Co., Ltd. GPC (>98\%) and PC (>99\%) were purchased from Sigma-Aldrich Chemical (Shanghai, China). PLA 1 (Lecitase ${ }^{\circledR}$ Ultra) is a $s n-1$ specific and proteinengineered carboxylic ester hydrolase (EC 3.1.1.3), which is extracted from Thermomyces lanuginosus/Fusarium oxysporum and produced by submerged fermentation of a genetically modified Aspergillus oryzae microorganism (activity, $10 \mathrm{KLU} \mathrm{g}^{-1}$; temperature, 40-60 $\left.{ }^{\circ} \mathrm{C} ; \mathrm{pH}, 5-9\right)$, and was obtained from Novozyme Biotechnology Co., Ltd (China). $\mathrm{PLA}_{2}$ is a $s n-2$ specific hydrolase (EC 3.1.1.4) extracted from genetically modified Streptomyces violaceoruber (LysoMax Oil; activity, 900-1100 U $\mathrm{g}^{-1}$; temperature, $\left.35-50{ }^{\circ} \mathrm{C} ; \mathrm{pH}, 5-8\right)$, and was obtained from DuPont Danisco. DSM Co., Ltd (China). Methanol and chloroform were HPLC grade and obtained from Fisher (Fair Lawn, NJ, USA). Ultrapure water was made in laboratory. The other solvents were all of analytical grade (Tianjin Kemiou Chemical Reagent Co., Ltd., Tianjin, China).
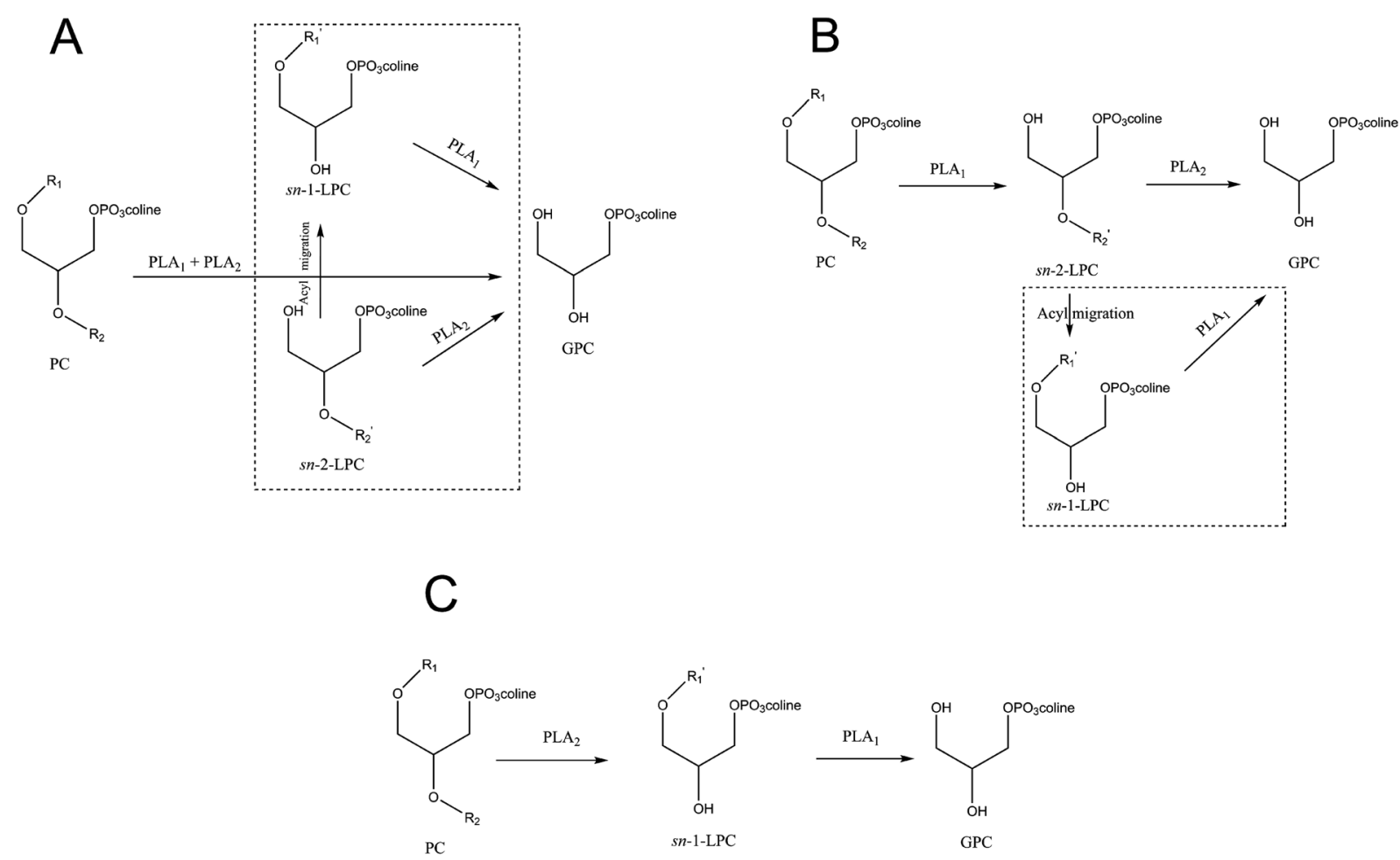

Fig. 2 Schemes of GPC enzymatic preparation from PC via PLA $A_{1}+A_{2}(A), P L A_{1} \rightarrow A_{2}(B)$ and $P L A_{2} \rightarrow A_{1}(C)$. 


\subsection{Emulsification of soybean concentrated phospholipid}

Soybean concentrated phospholipid was mixed with water in $250 \mathrm{~mL}$ round-bottom flask with magnetic agitation at $500 \mathrm{rpm}$ for $30 \mathrm{~min}$, and then homogenize it at $10000 \mathrm{rpm}$ for $5 \mathrm{~min}$ with a high-speed shear dispersing emulsifier (Fluko FA28, Shanghai, China) to obtain a certain concentration of mixture.

\subsection{Enzymatic preparation of GPC}

The obtained mixture with different concentrations was hydrolyzed by $\mathrm{PLA}_{1}$ and $\mathrm{PLA}_{2}$ at various temperatures and $\mathrm{pH}$ with a magnetic stirrer. The phospholipases were added to the reaction system by means of the following ways.

(I) $\mathrm{PLA}_{1}+\mathrm{A}_{2}$ : $\mathrm{PLA}_{1}$ and $\mathrm{PLA}_{2}$ were added at the same time (Fig. 2A).

(II) $\mathrm{PLA}_{1} \rightarrow \mathrm{A}_{2}$ : PLA $_{1}$ was firstly added for a certain time, and then $\mathrm{PLA}_{2}$ was added (Fig. 2B).

(III) PLA $_{2} \rightarrow \mathrm{A}_{1}$ : PLA $_{2}$ was firstly added for a certain time, and then $\mathrm{PLA}_{1}$ was added (Fig. 2C).

\subsection{GPC isolation}

Once the reaction was finished, a $3 \mathrm{~g}$ of the reaction product was dehydrated in vacuum at $80{ }^{\circ} \mathrm{C}$. Then, $5 \mathrm{~mL}$ of acetone was added, and the mixtures were shaken vigorously using a vortex mixer. This process was repeated 3 times. After the oil was removed, acetone was evaporated in vacuum at $40{ }^{\circ} \mathrm{C}$. The mixed solvents of chloroform and methanol $(\mathrm{v} / \mathrm{v}, 2: 1)$ were added with shaking, and the mixture was centrifuged at $10000 \mathrm{rpm}$ for $10 \mathrm{~min}$. The upper layer was filtered through a $0.22 \mu \mathrm{m}$ polypropylene filter and used for the analysis of GPC.

\subsection{GPC analysis}

The analysis of GPC was analyzed by high-performance liquid chromatography (Agilent 1260) equipped with an evaporative light scattering detection (ELSD). The ELSD was set at $65^{\circ} \mathrm{C}$ with a nitrogen gas flow rate of $1.6 \mathrm{~L} \mathrm{~min}^{-1}$. The separation procedure was carried out on a SunFire ${ }^{\mathrm{TM}}$ Prep Silica column $(5 \mu \mathrm{m}$, $4.6 \times 250 \mathrm{~mm}$, Waters, USA) and eluted with a binary gradient of methanol (A) and water (B). The proportion of elution $B$ increased from $15 \%$ to $25 \%$ within the first $7 \mathrm{~min}$, then increased to $30 \%$ within $5 \mathrm{~min}$, and decreased to $15 \%$ within $0.1 \mathrm{~min}$ and maintained for $6.9 \mathrm{~min}$. The flow rate was 1.0 $\mathrm{mL} \min ^{-1}$, and the injection volume was $10 \mu \mathrm{L}$. The concentrations of GPC and PC were measured using the external standard method. The yield of GPC and the conversion of PC were calculated as follows:

$$
\begin{gathered}
\text { Yield of } \mathrm{GPC}(\%)=\frac{C_{\mathrm{GPC}} \times V}{M_{\mathrm{GPC}}} \times 100 \% \\
\text { Conversion of } \mathrm{PC}(\%)=\frac{\left(C_{0} \times V_{0}-C_{1} \times V_{1}\right)}{C_{0} \times V_{0}} \times 100 \%
\end{gathered}
$$

where $C_{\mathrm{GPC}}$ is the GPC concentration in the sample; $V$ is the volume of the sample; $M_{\mathrm{GPC}}$ is the theoretical mass of GPC; $C_{0}$ and $V_{0}$ are the concentration and volume of PC in the sample before reaction, while $C_{1}$ and $V_{1}$ are the concentration and volume of $\mathrm{PC}$ in the sample after reaction.

\subsection{Statistical analysis}

The experiments were carried out at least in triplicate, and the results were expressed as average. One-way analysis of variance was adopted to identify differences. Statistical significance was considered at $P<0.05$.

\section{Results and discussion}

The soybean concentrated phospholipid was mainly composed of PC, phosphatidylethanolamine, phosphatidylinositol, phosphatidic acid and a small amount of $s n$-2-LPC. GPC was not detected in the raw material. The PC and GPC standards were used to build the calibration curves (Fig. 3), which were necessary to carry out the quantitative analysis of the remaining PC and generated GPC. In order to easily understand the paper, a general scheme of this study was shown in Fig. 4 .

\subsection{Effect of reaction time on the preparation of GPC}

In order to provide a reference for the total reaction time of the combinational phospholipases, the time course of PC conversion in enzymatic hydrolysis catalyzed by $\mathrm{PLA}_{1}$ and $\mathrm{PLA}_{2}$ was determined. As shown in Fig. 5, the PC conversion catalyzed by
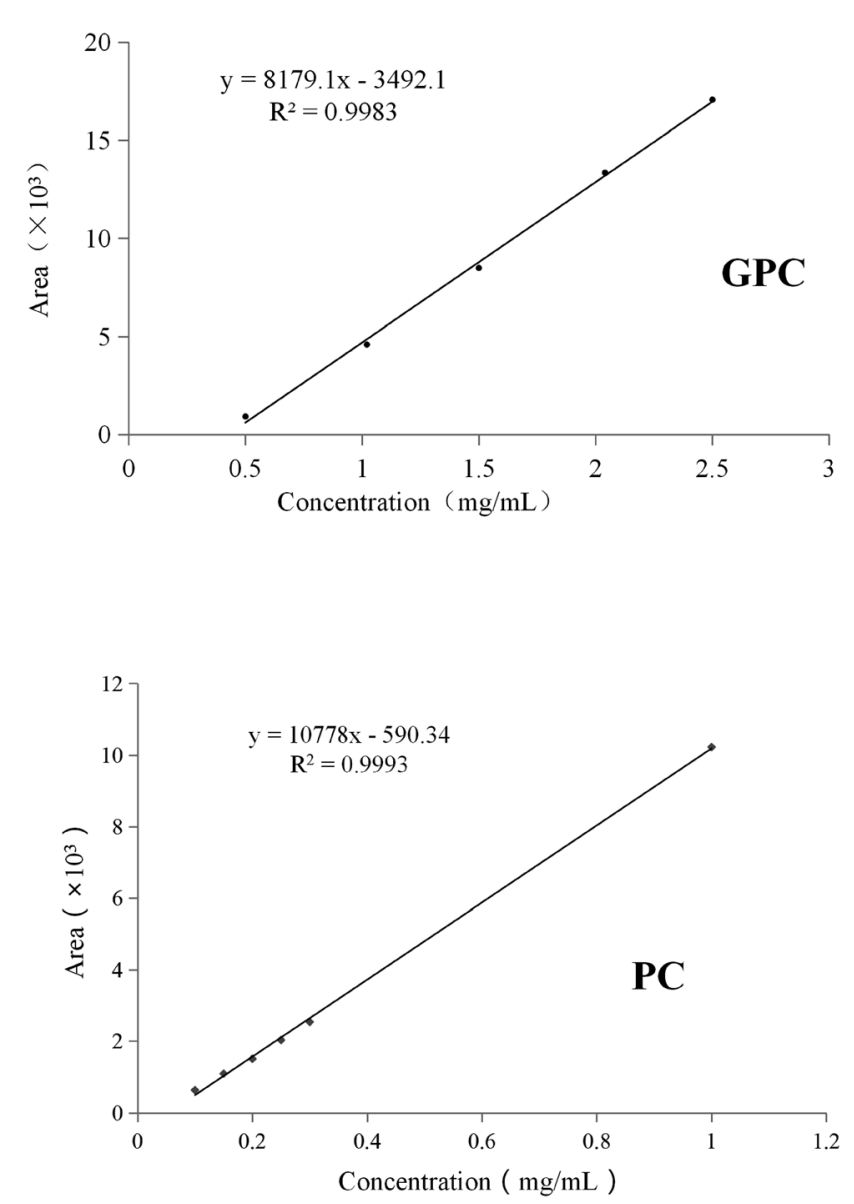

Fig. 3 Calibration curves for quantification of GPC and PC. 


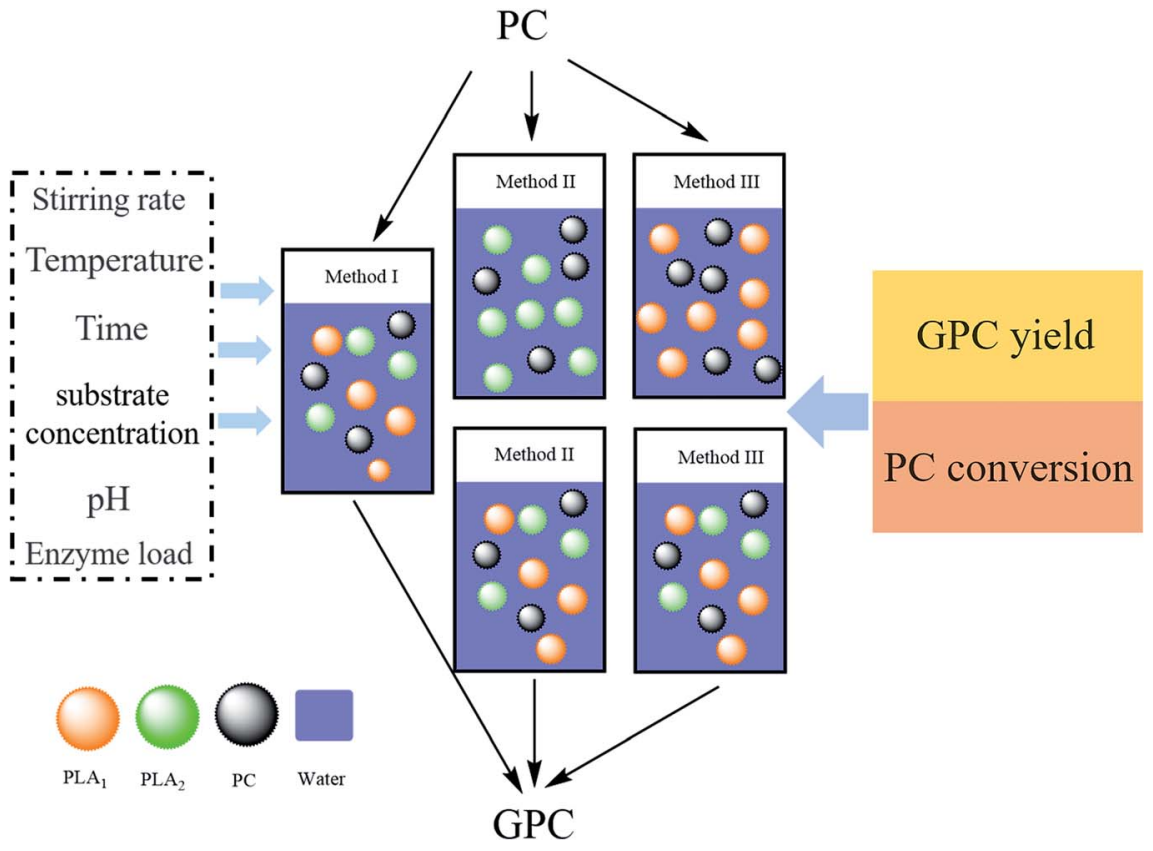

Fig. 4 A general scheme of this study.

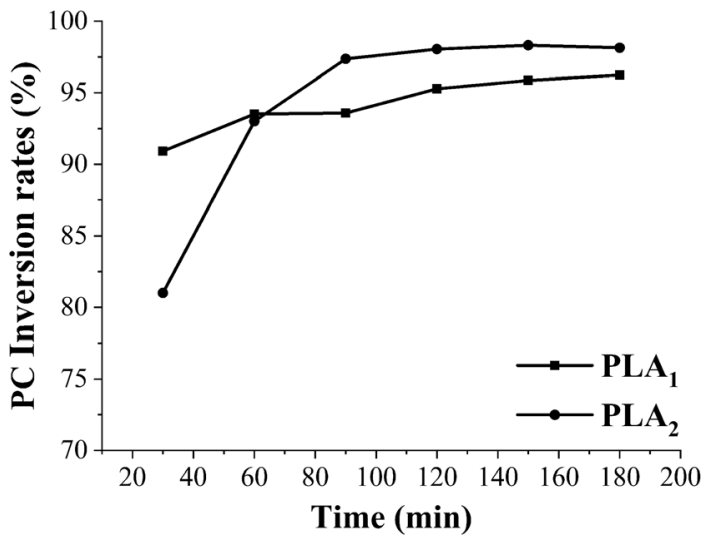

Fig. 5 Time-course of PC conversion in enzymatic hydrolysis catalyzed by $\mathrm{PLA}_{1}(\mathbf{\square})$ and $\mathrm{PLA}_{2}(\mathbf{O})$. Reaction conditions: temperature, $40{ }^{\circ} \mathrm{C}, \mathrm{pH}, 5.5$, substrate concentration, $10 \%, \mathrm{PLA}_{1}$ load, 1.50 wt $\%, \mathrm{PLA}_{2}$ load, 1.50 wt\%, stirring rate, $500 \mathrm{rpm}$.

$\mathrm{PLA}_{2}$ reached balanced at $90 \mathrm{~min}$, whereas there was no significant difference in the PC conversion catalyzed by PLA . Therefore, in order to adequately hydrolyze PC with $\mathrm{PLA}_{1}$ and $\mathrm{PLA}_{2}$ for obtaining a high yield of GPC, the total reaction time of method II $\left(\mathrm{PLA}_{1} \rightarrow \mathrm{A}_{2}\right.$ ) and method III $\left(\mathrm{PLA}_{2} \rightarrow \mathrm{A}_{1}\right)$ were determined to be $180 \mathrm{~min}$ and $120 \mathrm{~min}$, while the shortest reaction time of $\mathrm{PLA}_{2}$ in method II $\left(\mathrm{PLA}_{1} \rightarrow \mathrm{A}_{2}\right)$ and $\mathrm{PLA}_{1}$ in method III ( $\mathrm{PLA}_{2} \rightarrow \mathrm{A}_{1}$ ) were set as $90 \mathrm{~min}$ and $30 \mathrm{~min}$.

The influence of reaction time in method $\mathrm{I}\left(\mathrm{PLA}_{1}+\mathrm{A}_{2}\right)$ on the GPC yield and PC conversion in enzymatic hydrolysis was shown in Fig. 6A. The GPC yield increased with reaction time during 20-60 $\mathrm{min}$, and reached equilibrium at $60 \mathrm{~min}$ (50.00\%). A similar trend was observed in the PC conversion. The influences of the respective reaction time of $\mathrm{PLA}_{1}$ and $\mathrm{PLA}_{2}$ in method II $\left(\mathrm{PLA}_{1} \rightarrow \mathrm{A}_{2}\right)$ and method III $\left(\mathrm{PLA}_{2} \rightarrow \mathrm{A}_{1}\right)$ on the GPC yield and $\mathrm{PC}$ conversion were shown in Fig. $6 \mathrm{~B}$ and $\mathrm{C}$, respectively. As the reaction time of $\mathrm{PLA}_{1}$ in method II ( $\mathrm{PLA}_{1} \rightarrow$ $\mathrm{A}_{2}$ ) increased from $15 \mathrm{~min}$ to $90 \mathrm{~min}$, there was little difference in the GPC yield and PC conversion, which indicated that the reaction time of $\mathrm{PLA}_{1}$ had little effect on the GPC yield and PC conversion when the total time was constant. However, GPC yield in method III $\left(\mathrm{PLA}_{2} \rightarrow \mathrm{A}_{1}\right)$ increased by $14.98 \%$ with the reaction time of $\mathrm{PLA}_{2}$ from $15 \mathrm{~min}$ to $60 \mathrm{~min}$ and reached equilibrium at $60 \mathrm{~min}$, which was $18.50 \%$ higher than that in method I $\left(\mathrm{PLA}_{1}+\mathrm{A}_{2}\right)$. In terms of the three methods, when the reaction time was appropriate and enough, there was no obvious difference in the PC conversion (>95\%), whereas GPC yield was method III $\left(\mathrm{PLA}_{2} \rightarrow \mathrm{A}_{1}\right)>\operatorname{method~I~}\left(\mathrm{PLA}_{1}+\mathrm{A}_{2}\right)>$ method II ( $\mathrm{PLA}_{1} \rightarrow \mathrm{A}_{2}$ ), and the total reaction time was method I $\left(\mathrm{PLA}_{1}+\mathrm{A}_{2}\right)<\operatorname{method}$ III $\left(\mathrm{PLA}_{2} \rightarrow \mathrm{A}_{1}\right)<\operatorname{method}$ II $\left(\mathrm{PLA}_{1} \rightarrow \mathrm{A}_{2}\right)$. These results could be explained that the primary hydrolysate $\left(s n\right.$-2-LPC) of method II ( PLA $_{1} \rightarrow \mathrm{A}_{2}$ ) was unstable and easily converted into $s n$-1-LPC, which reduced the catalytic efficiency of $\mathrm{PLA}_{1}$. Compared with method I $\left(\mathrm{PLA}_{1}+\mathrm{A}_{2}\right), \mathrm{PLA}_{2}$ can completely act on PC at the initial stage of method III ( $\mathrm{PLA}_{2} \rightarrow$ $\mathrm{A}_{1}$ ) to generate a large number of stable $s n$-1-LPC and reduce acyl migration, and then $\mathrm{PLA}_{1}$ was added to completely act on $s n$-1-LPC, which improved the catalytic efficiency of $\mathrm{PLA}_{2}$. In addition, the reaction time of method III $\left(\mathrm{PLA}_{2} \rightarrow \mathrm{A}_{1}\right)$ was shorter than that of single phospholipase. ${ }^{\mathbf{2 3 , 2 4 , 2 8}}$

In terms of method I $\left(\mathrm{PLA}_{1}+\mathrm{A}_{2}\right)$ and method III $\left(\mathrm{PLA}_{2} \rightarrow \mathrm{A}_{1}\right)$, $\mathrm{PLA}_{1}$ and $\mathrm{PLA}_{2}$ act on the substrates together at the second stage, whereas only $\mathrm{PLA}_{2}$ is used for catalytic hydrolysis at the initial stage in method III (PLA $\left.\rightarrow \mathrm{A}_{1}\right)$. However, the GPC yield of method III ( $\mathrm{PLA}_{2} \rightarrow \mathrm{A}_{1}$ ) was higher than that of method I $\left(\mathrm{PLA}_{1}+\mathrm{A}_{2}\right)$, which means that the catalytic efficiency of $\mathrm{PLA}_{2}$ was higher than the concerted effect of $\mathrm{PLA}_{1}$ and $\mathrm{PLA}_{2}$ at the initial stage. This phenomenon might be due to the competition between the two phospholipases. In addition, in terms of method II $\left(\mathrm{PLA}_{1} \rightarrow \mathrm{A}_{2}\right)$ and method III $\left(\mathrm{PLA}_{2} \rightarrow \mathrm{A}_{1}\right)$, the 

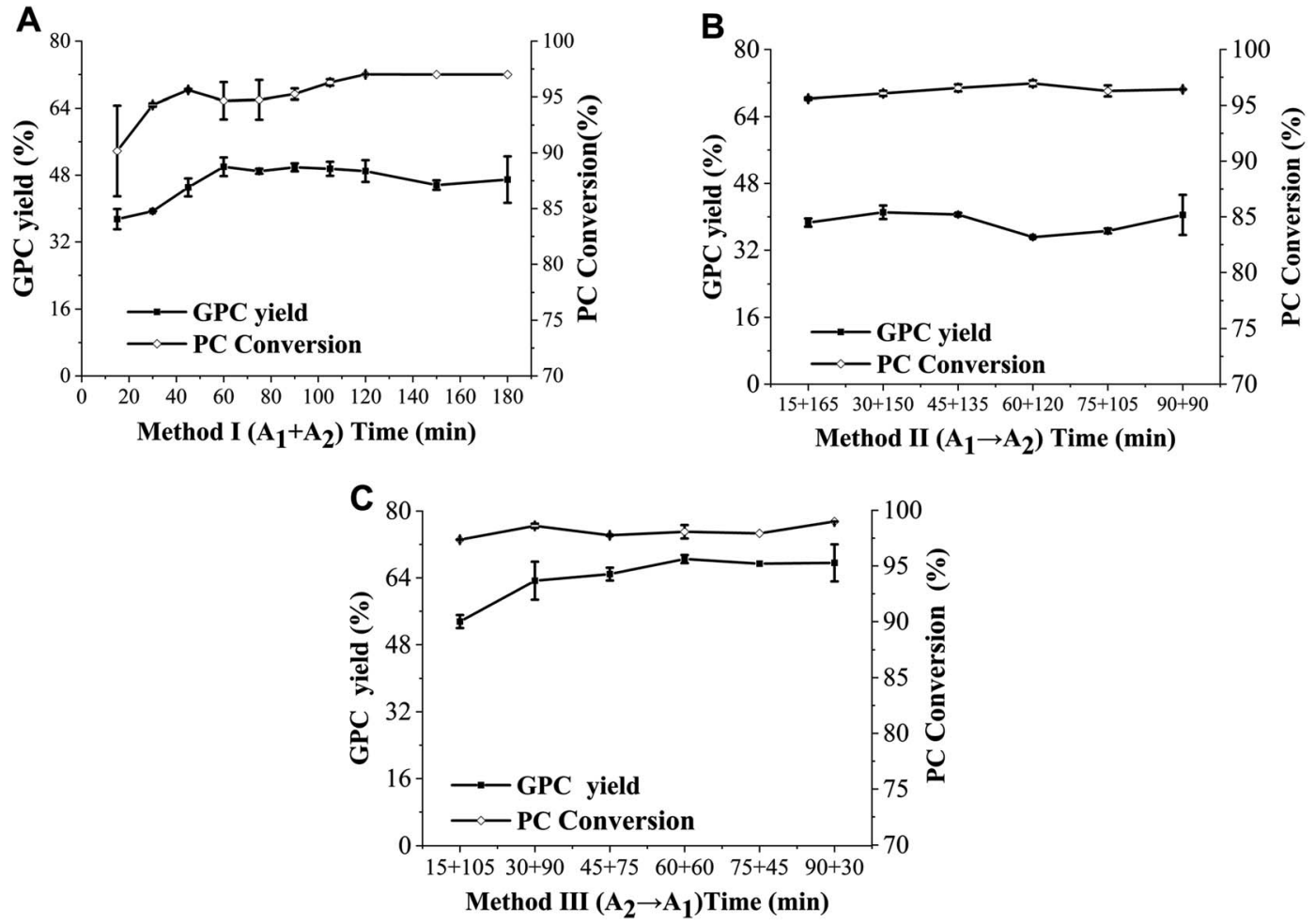

Fig. 6 Effect of reaction time of method I $\left(P L A_{1}+A_{2}\right)(A)$, method II $\left(P L A_{1} \rightarrow A_{2}\right)(B)$ and method III $\left(P L A_{2} \rightarrow A_{1}\right)(C)$ on the GPC yield $(\mathbf{\square})$ and PC

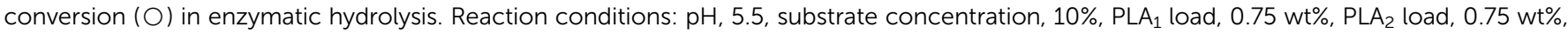
temperature, $40{ }^{\circ} \mathrm{C}$, stirring rate, $500 \mathrm{rpm}$.

concerted catalysis of $\mathrm{PLA}_{1}$ and $\mathrm{PLA}_{2}$ act on the substrates at the second stage, whereas $\mathrm{PLA}_{1}$ and $\mathrm{PLA}_{2}$ catalyze the substrates at the initial stage, respectively. The GPC yield of method II (PLA $\rightarrow A_{2}$ ) was lower than that of method III ( PLA $\left._{2} \rightarrow A_{1}\right)$, which was related to the easier acyl migration of the primary hydrolysate of the former method.

\subsection{Effect of reaction temperature on the preparation of} GPC

As reaction temperature increased, the GPC yields of method I $\left(\mathrm{PLA}_{1}+\mathrm{A}_{2}\right)$ and method III $\left(\mathrm{PLA}_{2} \rightarrow \mathrm{A}_{1}\right)$ firstly increased from
$30{ }^{\circ} \mathrm{C}$ to $40{ }^{\circ} \mathrm{C}$, then significantly decreased from $40{ }^{\circ} \mathrm{C}$ to $70{ }^{\circ} \mathrm{C}$, whereas there was no significant difference in method II ( $\mathrm{PLA}_{1}$ $\rightarrow A_{2}$ ) (Fig. 7A). In detail, the GPC yield of method III (PLA $\rightarrow$ $\mathrm{A}_{1}$ ) reached the highest level $(58.68 \%)$ at $40{ }^{\circ} \mathrm{C}$, which was $9.26 \%$ higher than that of method I $\left(\mathrm{PLA}_{1}+\mathrm{A}_{2}\right)$ and nearly $20 \%$ higher than that of method II ( PLA $\left._{1} \rightarrow \mathrm{A}_{2}\right)$ at the optimum temperatures. This was because there was less acyl migration in method III $\left(\mathrm{PLA}_{2} \rightarrow \mathrm{A}_{1}\right)$. Moreover, both of the optimal temperatures in method I $\left(\mathrm{PLA}_{1}+\mathrm{A}_{2}\right)$ and method III $\left(\mathrm{PLA}_{2} \rightarrow \mathrm{A}_{1}\right)$ were $40{ }^{\circ} \mathrm{C}$, while it was $60{ }^{\circ} \mathrm{C}$ in method II $\left(\mathrm{PLA}_{1} \rightarrow \mathrm{A}_{2}\right)$. The former was closer to the optimal temperature of $\mathrm{PLA}_{2}$, and the latter was
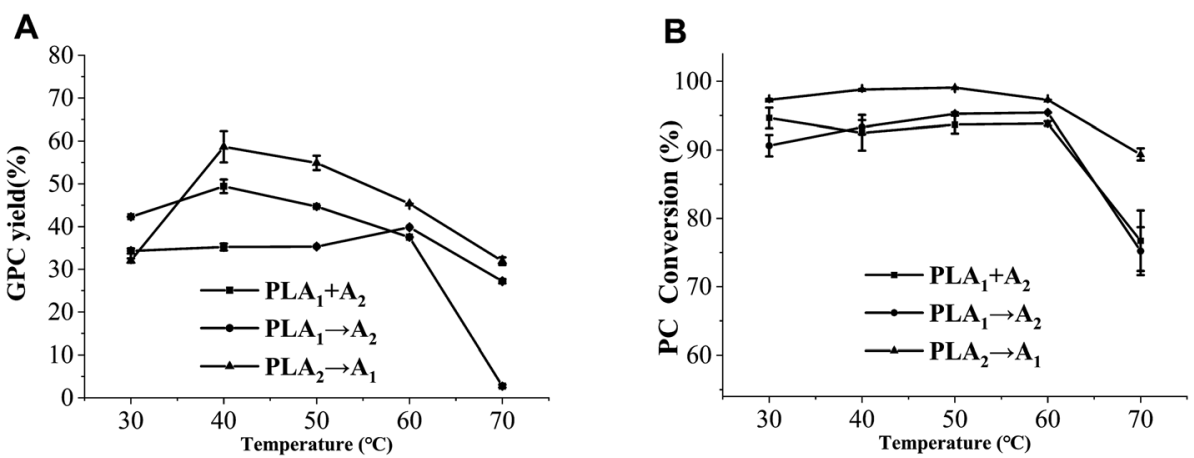

Fig. 7 Effect of temperature on the GPC yield (A) and PC conversion (B) in enzymatic hydrolysis. Method I (PLA $\left.1+A_{2}\right)(\boldsymbol{\square})$, method II (PLA $\left.\rightarrow A_{2}\right)$ $(\mathbf{O})$, method III $\left(P L A_{2} \rightarrow A_{1}\right)(\boldsymbol{\Delta})$. Reaction conditions: $\mathrm{pH}, 5.5$, substrate concentration, 10\%, PLA $\mathrm{A}_{1}$ load, 0.75 wt\%, PLA $\mathrm{A}_{2}$ load, 0.75 wt\%, reaction time of method I $\left(P L A_{1}+A_{2}\right), 60$ min, reaction time of $P L A_{1}$ and $P L A_{2}$ in method II $\left(P L A_{1} \rightarrow A_{2}\right), 30$ and 150 min, reaction time of PLA $A_{2}$ and $P L A_{1}$ in method III $\left(P L A_{2} \rightarrow A_{1}\right), 60$ and 60 min, stirring rate, $500 \mathrm{rpm}$. 
A

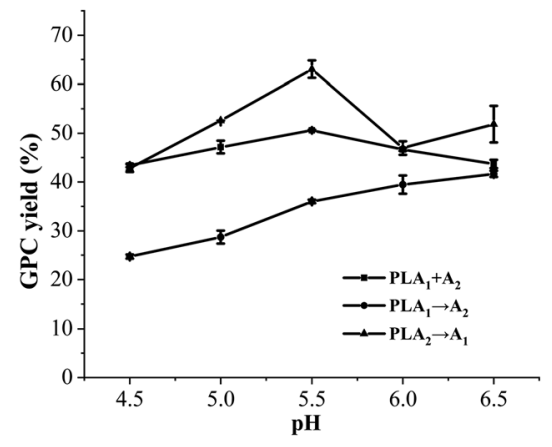

B

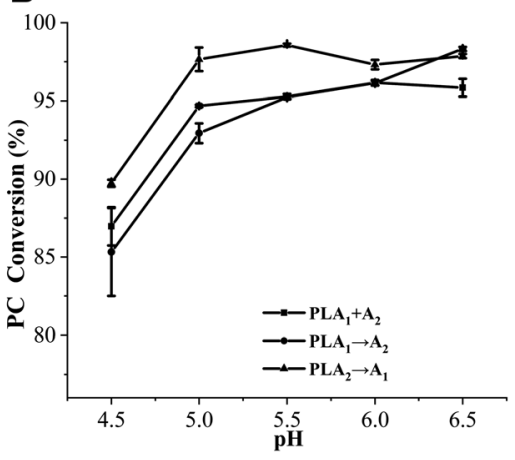

Fig. 8 Effect of pH on the GPC yield (A) and PC conversion (B) in enzymatic hydrolysis. Method I $\left(P L A_{1}+A_{2}\right)(\boldsymbol{\square})$, method II $\left(P L A_{1} \rightarrow A_{2}\right)(\bullet)$, method III $\left(P L A_{2} \rightarrow A_{1}\right)(\boldsymbol{\Delta})$. Reaction conditions: substrate concentration, 10\%, PLA load, $0.75 w t \%, P L A_{2}$ load, 0.75 wt $\%$, reaction time of method I $\left(P L A_{1}+A_{2}\right), 60$ min, reaction time of PLA $A_{1}$ and PLA in method II $\left(P L A_{1} \rightarrow A_{2}\right), 30$ and 150 min, reaction time of PLA $A_{2}$ and PLA in method III $\left(P L A_{2}\right.$ $\left.\rightarrow A_{1}\right), 60$ and $60 \mathrm{~min}$, stirring rate, $500 \mathrm{rpm}$, temperatures of method I $\left(P L A_{1}+A_{2}\right)$ and method III (PLA $\left.A_{2} \rightarrow A_{1}\right), 40^{\circ} \mathrm{C}$, temperature of method II $\left(\mathrm{PLA}_{1} \rightarrow \mathrm{A}_{2}\right), 60^{\circ} \mathrm{C}$.

closer to the optimal temperature of $\mathrm{PLA}_{1}$, which indicated that the two phospholipases might be competitive during the catalytic reaction. ${ }^{23,29}$

As seen from Fig. 7B, there was no obvious difference in the PC conversion from $30{ }^{\circ} \mathrm{C}$ to $60^{\circ} \mathrm{C}$, whereas the PC conversion significantly decreased from $60{ }^{\circ} \mathrm{C}$ to $70{ }^{\circ} \mathrm{C}$. This trend was found in the three methods. However, the PC conversions of method III $\left(\mathrm{PLA}_{2} \rightarrow \mathrm{A}_{1}\right)$ within the temperature range were higher than those of the other methods.

\subsection{Effect of $\mathrm{pH}$ on the preparation of GPC}

The $\mathrm{pH}$ of the reaction mixture not only affects the active site of phospholipase, but also affects the acyl migration of $s n-2$ LPC. ${ }^{30-32}$ As shown in Fig. 8A, a positive correlation between $\mathrm{pH}$ and GPC yield in method II ( $\mathrm{PLA}_{1} \rightarrow \mathrm{A}_{2}$ ) was found, and the GPC yield reached the maximum $(41.67 \%)$ at $\mathrm{pH}$ 6.5. This is because low $\mathrm{pH}$ can promote the acyl migration of the hydrolysate ( $s n-2-\mathrm{LPC})$ in the early stage. ${ }^{33}$ However, the GPC yield of method I $\left(\mathrm{PLA}_{1}+\mathrm{A}_{2}\right)$ firstly increased and then decreased with the increase of $\mathrm{pH}$, and obtained the highest level (50.60\%) at
$\mathrm{pH}$ 5.5. Although a similar trend was also found in method III $\left(\mathrm{PLA}_{2} \rightarrow \mathrm{A}_{1}\right)$, the GPC yield was $12.46 \%$ higher than that of method I $\left(\mathrm{PLA}_{1}+\mathrm{A}_{2}\right)$ at $\mathrm{pH}$ 5.5. This situation might be caused by the fact that $\mathrm{PLA}_{1}$ and $\mathrm{PLA}_{2}$ were simultaneously added to the reaction system in method $\mathrm{I}\left(\mathrm{PLA}_{1}+\mathrm{A}_{2}\right)$, and the acidic environment of the reaction system accelerated the acyl migration of $s n$-2-LPC. However, the amount of PLA ${ }_{1}$ was definite, which led to the decrease of the GPC yield.

Similar to GPC yield, the PC conversion of method II (PLA 1 $\rightarrow \mathrm{A}_{2}$ ) continuously increased with the increase of $\mathrm{pH}$, whereas those of method I ( $\left.\mathrm{PLA}_{1}+\mathrm{A}_{2}\right)$ and method III $\left(\mathrm{PLA}_{2} \rightarrow \mathrm{A}_{1}\right)$ increased from 4.5 to 5.0 and reached balanced at 5.0 (Fig. 8B). In addition, some studies have reported that the optimum temperatures of $\mathrm{PLA}_{1}$ and $\mathrm{PLA}_{2}$ are 4-5 and neutral, respectively. ${ }^{27,34,35}$ According to our results, the optimum $\mathrm{pH}$ values of method I $\left(\mathrm{PLA}_{1}+\mathrm{A}_{2}\right)$ and method III $\left(\mathrm{PLA}_{2} \rightarrow \mathrm{A}_{1}\right)$ were 5.5 (in the optimum range of $\mathrm{PLA}_{1}$ and $\mathrm{PLA}_{2}$ ), which was lower than that of method II $\left(\mathrm{PLA}_{1} \rightarrow \mathrm{A}_{2}\right)$. This phenomenon indicated that the optimum $\mathrm{pH}$ of the combinational phospholipases was not consistent with those of single phospholipases.
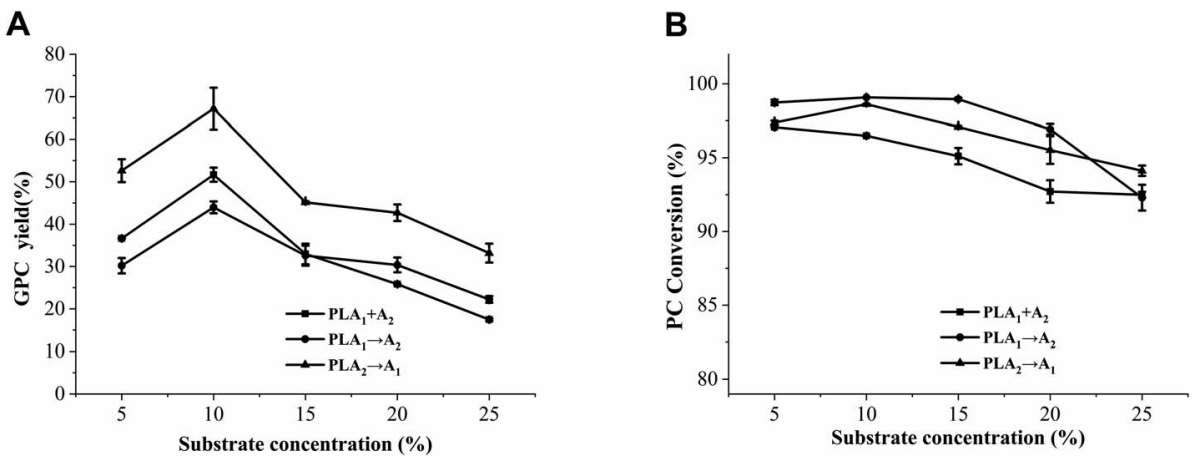

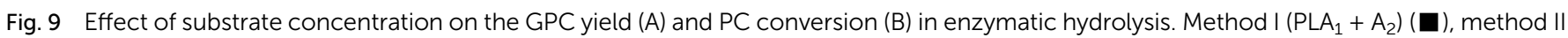
$\left(P L A_{1} \rightarrow A_{2}\right)(\bullet)$, method III $\left(P L A_{2} \rightarrow A_{1}\right)(\boldsymbol{\Delta})$. Reaction conditions: PLA load, 0.75 wt\%, PLA $A_{2}$ load, 0.75 wt\%, reaction time of method I $\left(P L A_{1}+A_{2}\right)$, 60 min, reaction time of $P L A_{1}$ and $P L A_{2}$ in method II $\left(P L A_{1} \rightarrow A_{2}\right), 30$ and 150 min, reaction time of $P L A_{2}$ and $P L A_{1}$ in method III $\left(P L A_{2} \rightarrow A_{1}\right), 60$ and $60 \mathrm{~min}$, stirring rate, $500 \mathrm{rpm}$, temperatures of method I $\left(P L A_{1}+A_{2}\right)$ and method III $\left(P L A_{2} \rightarrow A_{1}\right), 40{ }^{\circ} \mathrm{C}$, temperature of method II (PLA $\left.\rightarrow A_{2}\right)$, $60{ }^{\circ} \mathrm{C}, \mathrm{pH}$ of method I $\left(\mathrm{PLA} \mathrm{A}_{1}+\mathrm{A}_{2}\right)$ and method III $\left(\mathrm{PLA} \mathrm{A}_{2} \rightarrow \mathrm{A}_{1}\right), 5.5, \mathrm{pH}$ of method II $\left(\mathrm{PLA} \mathrm{A}_{1} \rightarrow \mathrm{A}_{2}\right), 6.5$. 


\subsection{Effect of substrate concentration on the preparation of GPC}

Phospholipid, oil and water can form an emulsion after homogenization. The mass and heat transfer of the reaction system are affected by emulsion viscosity, thus affecting the generation rate of GPC. As shown in Fig. 9, the PC conversion decreased with the increase of substrate concentration, whereas the GPC yield increased from $5 \%$ to $10 \%$ then decreased from $10 \%$ to $25 \%$. This trend was found in the three methods. In theory, when the reaction mixture concentration is relatively low, the reaction system viscosity is low, and the substrate exists as single molecules or small aggregates, which leads to a large reaction interface area in favor of GPC preparation. As substrate concentration continues to increase, the active sites of phospholipases become insufficient to completely hydrolyze the substrates, resulting in the decrease of the GPC yield and PC conversion. Similar results were also discovered by Lu et al. ${ }^{24}$

Although the optimal concentrations of the three methods was $10 \%$, the GPC yield of method III $\left(\mathrm{PLA}_{2} \rightarrow \mathrm{A}_{1}\right)$ was $23.92 \%$ higher than that of method II $\left(\mathrm{PLA}_{1} \rightarrow \mathrm{A}_{2}\right)$ and $15.53 \%$ higher than that of method I $\left(\mathrm{PLA}_{1}+\mathrm{A}_{2}\right)$. Moreover, the GPC yields of method III $\left(\mathrm{PLA}_{2} \rightarrow \mathrm{A}_{1}\right)$ at the substrate concentration range of $5-25 \%$ were higher than those of the other two methods. These results reflect the facts that the stepwise catalysis and adding order of the combinational phospholipases have an important influence on the preparation of GPC.

\subsection{Effect of enzyme load on the preparation of GPC}

Many studies have confirmed the importance of enzyme load in the preparation of GPC. ${ }^{25,36}$ According to our preliminary experiments, it was found that the same amount of $\mathrm{PLA}_{1}$ and $\mathrm{PLA}_{2}$ was beneficial to improve the GPC yield. Thus, we only discuss the effect of total enzyme load on the GPC preparation in this paper. As shown in Fig. 10, when the enzyme load was 0.5-2.5\%, the GPC yield and PC conversion of method I $\left(\mathrm{PLA}_{1}+\right.$ $A_{2}$ ) were always higher than those of method II (PLA $\left.\rightarrow A_{2}\right)$, which was due to the reduction of the acyl migration of $s n$-2-LPC by adding $\mathrm{PLA}_{1}$ and $\mathrm{PLA}_{2}$ at the same time. Opposite to the other two methods, the GPC yield of method III $\left(\mathrm{PLA}_{2} \rightarrow \mathrm{A}_{1}\right)$ firstly increased then shapely decreased with the increase of enzyme load, which might be explained that excessive phospholipase might affect the binding probability of phospholipid and phospholipase. Luis et al. found that the initial rate had a significantly decrease when the lipase concentration was above $5 \%(\mathrm{~W} / \mathrm{W}) .{ }^{37}$ In addition, although the optimum enzyme load was $1.5 \%$ in method I $\left(\mathrm{PLA}_{1}+\mathrm{A}_{2}\right)$ and method III $\left(\mathrm{PLA}_{2} \rightarrow\right.$ $\mathrm{A}_{1}$ ), the GPC yield of method III ( $\mathrm{PLA}_{2} \rightarrow \mathrm{A}_{1}$ ) was $14.26 \%$ higher than that of method I $\left(\mathrm{PLA}_{1}+\mathrm{A}_{2}\right)$. These results indicated that the method, in which $\mathrm{PLA}_{2}$ is firstly added then PLA 1 is added, had a positive role on the reduction of the acyl migration of $s n-2$ LPC and was beneficial to the preparation of GPC at the relatively low enzyme load.

\subsection{Effect of stirring rate on the preparation of GPC}

Since this hydrolysis reaction was carried out in a heterogeneous system, the mixing intensity of the reaction mixture affected the rate of enzymatic reaction. The effect of stirring rate on the GPC yield and PC conversion was shown in Fig. 11. With different stirring rate, there was no significant difference in the PC conversion of method II ( $\left.\mathrm{PLA}_{1} \rightarrow \mathrm{A}_{2}\right)$ and method III ( $\mathrm{PLA}_{2}$ $\left.\rightarrow A_{1}\right)$, whereas that of method I (PLA $\left.1+A_{2}\right)$ firstly increased and then decreased. In terms of GPC yield, the three methods showed that it increased with stirring rate from 100 to $500 \mathrm{rpm}$, and then slightly decreased with stirring rate from 500 to $900 \mathrm{rpm}$. Li et al. also discovered that high stirring rate could result in the reduction of catalytic activity. ${ }^{38}$ In theory, with the increase of stirring rate, the interface area of substrate at the aqueous phase gradually increases, and the probability of phospholipase active sites on phospholipids also increases, which is beneficial to the increase of the GPC yield. However, high stirring rate will make the reaction mixture and phospholipases suffer too much centrifugal force, resulting in being thrown to the inner wall of the reactor and reducing the GPC yield.

Moreover, although the optimal stirring rate was $500 \mathrm{rpm}$ among the three methods, the GPC yield of method II (PLA $\rightarrow$ $\mathrm{A}_{2}$ ) was $13.33 \%$ higher than that of method I $\left(\mathrm{PLA}_{1}+\mathrm{A}_{2}\right)$, and $24.84 \%$ higher than that of method II $\left(\mathrm{PLA}_{1} \rightarrow \mathrm{A}_{2}\right)$. These
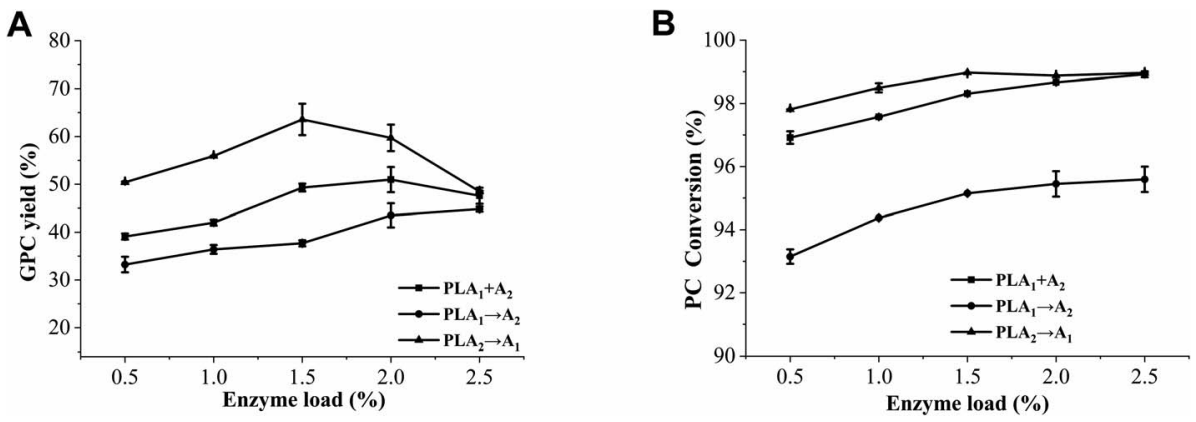

Fig. 10 Effect of enzyme load on the GPC yield (A) and PC conversion (B) in enzymatic hydrolysis. Method I (PLA $\left.A_{1}+A_{2}\right)(\boldsymbol{\square})$, method II (PLA $\rightarrow$ $\left.A_{2}\right)\left(-\right.$ ), method III $\left(P L A_{2} \rightarrow A_{1}\right)(\boldsymbol{\Delta})$. Reaction conditions: reaction time of method I $\left(P L A_{1}+A_{2}\right), 60$ min, reaction time of $P L A_{1}$ and $P L A_{2}$ in method II $\left(P L A_{1} \rightarrow A_{2}\right), 30$ and 150 min, reaction time of $P L A_{2}$ and $P L A_{1}$ in method III $\left(P L A_{2} \rightarrow A_{1}\right), 60$ and 60 min, stirring rate, 500 rpm, temperatures of method I $\left(P L A_{1}+A_{2}\right)$ and method III (PLA $\left.\rightarrow A_{1}\right), 40{ }^{\circ} \mathrm{C}$, temperature of method II $\left(P L A_{1} \rightarrow A_{2}\right), 60{ }^{\circ} \mathrm{C}$, pH of method I $\left(P L A_{1}+A_{2}\right)$ and method III $\left(\mathrm{PLA} \mathrm{A}_{2} \rightarrow \mathrm{A}_{1}\right), 5.5, \mathrm{pH}$ of method II (PLA $\left.\rightarrow \mathrm{A}_{2}\right), 6.5$, substrate concentration, $10 \%$. 

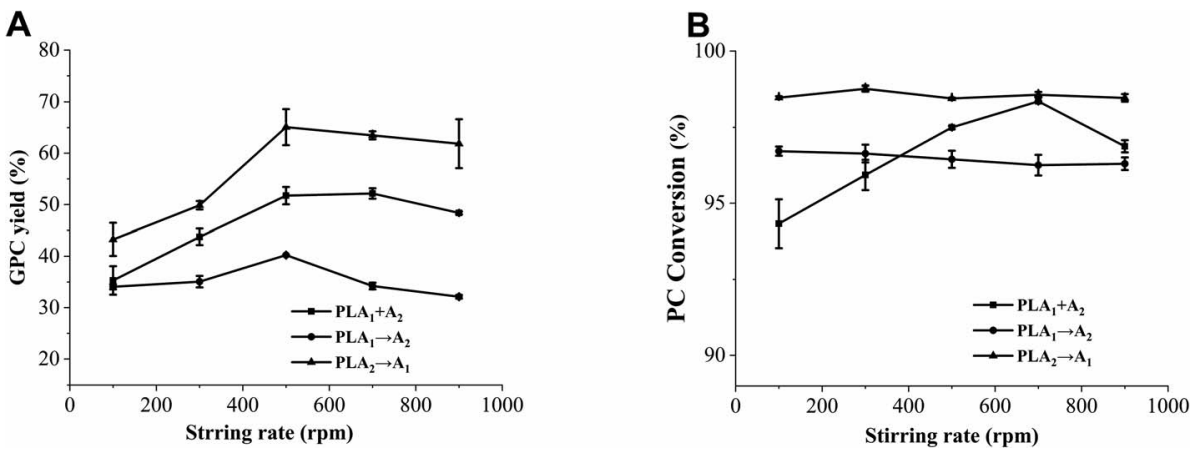

Fig. 11 Effect of stirring rate on the GPC yield (A) and PC conversion (B) in enzymatic hydrolysis. Method I (PLA $\left.1+A_{2}\right)(\boldsymbol{\square})$, method II (PLA $\left.\rightarrow A_{2}\right)$ $(\boldsymbol{O})$, method III $\left(P L A_{2} \rightarrow A_{1}\right)(\boldsymbol{\Delta})$. Reaction conditions: reaction time of method I $\left(P L A_{1}+A_{2}\right), 60$ min, reaction time of PLA $A_{1}$ and $P L A_{2}$ in method II $\left(P L A_{1} \rightarrow A_{2}\right), 30$ and 150 min, reaction time of $P L A_{2}$ and $P L A_{1}$ in method III $\left(P L A_{2} \rightarrow A_{1}\right), 60$ and 60 min, temperatures of method I $\left(P L A_{1}+A_{2}\right)$ and method III $\left(P L A_{2} \rightarrow A_{1}\right), 40{ }^{\circ} \mathrm{C}$, temperature of method II $\left(P L A_{1} \rightarrow A_{2}\right), 60{ }^{\circ} \mathrm{C}, \mathrm{pH}$ of method I $\left(P L A_{1}+A_{2}\right)$ and method III $\left(P L A_{2} \rightarrow A_{1}\right), 5.5$, ph of method II $\left(P L A_{1} \rightarrow A_{2}\right), 6.5$, substrate concentration, 10\%, PLA load, 0.75 wt\%, PLA $A_{2}$ load, 0.75 wt\%.

results reflected that stirring rate had an obvious influence on hydrolysis efficiency, but had little influence on the different stepwise catalysis methods.

\section{Conclusions}

This study innovatively found that the addition method of $\mathrm{PLA}_{1}$ and $\mathrm{PLA}_{2}$ had a vital influence on the preparation of GPC. In particular, method III ( $\mathrm{PLA}_{2} \rightarrow \mathrm{A}_{1}$ ) was superior to method I $\left(\mathrm{PLA}_{1}+\mathrm{A}_{2}\right)$, followed by method II $\left(\mathrm{PLA}_{1} \rightarrow \mathrm{A}_{2}\right)$. The main reason was that the former method could effectively reduce the occurrence of acyl migration and the competition between PLA and $\mathrm{PLA}_{2}$, thus shortening the reaction time and improving the GPC yield. In addition, temperature, $\mathrm{pH}$ and enzyme load had significant effects on the different addition methods of $\mathrm{PLA}_{1}$ and $\mathrm{PLA}_{2}$, whereas reaction time, substrate concentrate and stirring rate had little effect on them. These results could provide a novel approach for the preparation of GPC catalyzed by combinational phospholipases in future.

\section{Conflicts of interest}

There are no conflicts of interest to declare.

\section{Acknowledgements}

This work was financially supported by the National Key Research and Development Program of China (2018YFD0401102).

\section{References}

1 Y. Du, W. He, W. Zhou and X. Li, Chem. Commun., 2019, 55, 8434-8437.

2 W. S. Arrata, T. Burt and S. Corder, Fertil. Steril., 1978, 30, 329-333.

3 T. Ziegenfuss, J. Landis and J. Hofheins, J. Int. Soc. Sports Nutr., 2008, 5, P15.
4 H. Komatsu, J. Westerman, G. T. Snoek, T. F. Taraschi and N. Janes, Biochim. Biophys. Acta, 2003, 1635, 67-74.

5 J. V. Greiner, T. Glonek, D. R. Korb, M. E. Lindsay and P. J. Oliver, Exp. Eye Res., 2020, 192, 107932.

6 A. Haider, Y. C. Wei, K. Lim, A. D. Barbosa, C. H. Liu, U. Weber, M. Mlodzik, K. Oras, S. Collier, M. M. Hussain, L. Dong, S. Patel, A. Alvarez-Guaita, V. Saudek, B. J. Jenkins, A. Koulman, M. K. Dymond, R. C. Hardie, S. Siniossoglou and D. B. Savage, Dev. Cell, 2018, 45, 481-495.

7 L. Marcus, J. Soileau, L. W. Judge and D. Bellar, J. Int. Soc. Sports Nutr., 2017, 14, 39.

8 G. Strifler, E. Tuboly, A. Gorbe, M. Boros, D. Pecz and P. Hartmann, PLoS One, 2016, 11, e0166682.

9 S. H. Lee, B. Y. Choi, J. H. Kim, A. R. Kho, M. Sohn, H. K. Song, H. C. Choi and S. W. Suh, Brain Res., 2017, 1654, 66-76.

10 J. M. Park, K. A. De Castro, H. Ahn and H. Rhee, Bull. Korean Chem. Soc., 2010, 39, 2689-2691.

11 C. R. Scholfield, J. Am. Oil Chem. Soc., 1981, 58, 889-892.

12 H. Brockerhoff and M. Yurkowski, Can. J. Biochem., 1965, 43, 1777.

13 E. Baer, J. Am. Oil Chem. Soc., 1965, 42, 257-266.

14 G. Schmidt, B. Hershman and S. J. Thannhauser, J. Biol. Chem., 1945, 161, 523-536.

15 H.-Y. Li, X.-L. Zhang, J.-B. Zhang, T.-T. Zhang and B.-X. Zhao, Int. J. Chem. Kinet., 2014, 46, 169-175.

16 B. Marrapu, L. K. Mallampalli, S. S. Kaki and B. N. P. Rachapudi, Eur. J. Lipid Sci. Technol., 2015, 117, 1049-1055.

17 Y. Iwasaki and T. Yamane, Adv. Biochem. Eng./Biotechnol., 2004, 90, 151-171.

18 E. D. Yushkova, E. A. Nazarova, A. V. Matyuhina, A. O. Noskova, D. O. Shavronskaya, V. V. Vinogradov, N. N. Skvortsova and E. F. Krivoshapkina, J. Agric. Food Chem., 2019, 67, 11553-11567.

19 M. Murakami, Proc. Jpn. Acad., Ser. B, 2017, 93, 677-702.

20 A. M. Astudillo, M. A. Balboa and J. Balsinde, Biochim. Biophys. Acta, Mol. Cell Biol. Lipids, 2019, 1864, 772-783. 
21 M. Murakami, Biochim. Biophys. Acta, Mol. Cell Biol. Lipids, 2019, 1864, 763-765.

22 H. Li, Y. Pang, X. Wang, X. Cao, X. He, K. Chen, G. Li, P. Ouyang and W. Tan, RSC Adv., 2019, 9, 6548-6555.

23 K. Zhang, Y. Liu and X. Wang, Eur. J. Lipid Sci. Technol., 2012, 114, 1254-1260.

24 Y. Lu, A. Zhang, X. Wang, N. Hao, K. Chen and P. Ouyang, Biocatal. Biotransform., 2019, 37, 361-366.

25 J. Kim, Y. Song, S. J. Lee, J. E. Lee, M. Y. Chung, I. H. Kim and B. H. Kim, Biotechnol. Prog., 2020, 36, e2910.

26 A. F. Vikbjerg, H. Mu and X. Xu, J. Am. Oil Chem. Soc., 2006, 83, 609-614.

27 F. Blasi, L. Cossignani, A. Maurizi, M. S. Simonetti and P. Damiani, Ital. J. Food Sci., 2008, 20, 39-47.

28 H. J. Bang, I. H. Kim and B. H. Kim, Food Chem., 2016, 190, 201-206.

29 J. Choi, W. Zhang, X. Gu, X. Chen, L. Hong, J. M. Laird and R. G. Salomon, Chem. Res. Toxicol., 2011, 24, 111-118.

30 D. Adlercreutz, H. Budde and E. Wehtje, Biotechnol. Bioeng., 2002, 78, 403-411.
31 R. Durrani, F. I. Khan, S. Ali, Y. Wang and B. Yang, Biomolecules, 2020, 10, 231.

32 R. A. Bouley, V. Hinkovska-Galcheva, J. A. Shayman and J. J. G. Tesmer, Biochemistry, 2019, 58, 1709-1717.

33 A. Pluckthun and E. A. Dennis, Biochemistry, 1982, 21, 17431750.

34 K. Clausen, Eur. J. Lipid Sci. Technol., 2001, 103, 333-340.

35 L. Poisson, M. Devos, S. Godet, F. Ergan and G. Pencreac'h, Biotechnol. Lett., 2009, 31, 743-749.

36 F. Blasi, L. Cossignani, M. S. Simonetti, M. Brutti, F. Ventura and P. Damiani, Enzyme Microb. Technol., 2006, 39, 14051408.

37 L. J. L. Giraldo, M. Laguerre, J. Lecomte, M.-C. FigueroaEspinoza, N. Barouh, B. Barea and P. Villeneuve, Enzyme Microb. Technol., 2007, 41, 721-726.

38 H. Li, X. Cao, Y. Lu, Y. Ni, X. Wang, Q. Lu, G. Li, K. Chen, P. Ouyang and W. Tan, Catalysts, 2019, 9, 237, DOI: 10.3390/catal9030237. 